\title{
Effect of cooling rate on crystal polymorphism in beta-nucleated isotactic polypropylene as revealed by a combined WAXS/FSC analysis
}

\author{
$\underline{\text { Anne M. Gohn }}{ }^{\mathrm{a}, \mathrm{c}}$, Alicyn M. Rhoades ${ }^{\mathrm{a}^{*}}$, Nichole Wonderling $^{\mathrm{b}}$, René Androsch ${ }^{\mathrm{c}}$ \\ Email Contact: amm6125@psu.edu \\ a School of Engineering, Penn State Behrend, 4701 College Drive, Erie, PA 16563, United States \\ b Materials Characterization Laboratory, N-003 Millennium Science Complex, Pennsylvania State \\ University, University Park, PA 16802, United States \\ c Interdisciplinary Center for Transfer-oriented Research in Natural Sciences, Martin Luther University \\ Halle-Wittenberg, 06009 Halle/Saale, Germany
}

The efficiency of linear trans $\gamma$-quinacridone to nucleate formation of $\beta$-crystals in isotactic polypropylene (iPP) at rapid cooling conditions has been evaluated by a combination of fast scanning chip calorimetry (FSC) and microfocus wide-angle X-ray scattering (WAXS). For samples containing different amount of $\gamma$-quinacridone, FSC cooling experiments revealed information about a critical cooling rate above which the crystallization temperature decreases to below $105^{\circ} \mathrm{C}$, that is, to temperatures at which the growth rate of $\alpha$-crystals is higher than that of $\beta$-crystals. Microfocus WAXS analysis was then applied to gain information about the competition of formation of $\beta$ - and $\alpha$-crystals in samples prepared at well-defined conditions of cooling at rates up to $1000 \mathrm{~K} / \mathrm{s}$ in the FSC. For iPP containing 1 and $500 \mathrm{ppm} \gamma$-quinacridone, the crystallization temperature is lower than $105^{\circ} \mathrm{C}$ on cooling faster about 10 and $70 \mathrm{~K} / \mathrm{s}$, respectively, which then on further increase of the cooling rate leads to a distinct reduction of the $\beta$-crystal fraction. The study may be considered as a first successful attempt to quantify and interpret $\beta$-crystal formation in iPP containing $\gamma$-quinacridone at processing-relevant cooling conditions in the shed of light of the different temperature-dependence of the growth rates of $\alpha$ - and $\beta$-crystals. These conditions can then be applied to mold filling simulations to predict microstructures resulting from the injection molding process. 